\title{
Information and Communication Technologies in the Contemporary Educational Process*
}

\author{
Vladimir Tsvyk \\ Faculty of Humanities and Social sciences \\ Department of Ethics \\ Peoples' Friendship University of Russia (RUDN University) \\ 6 Miklukho-Maklaya Street, Moscow, 117198, Russian \\ Federation \\ E-mail: tsvyk_va@university.ru
}

\author{
Irina Tsvyk \\ Department of Philosophy \\ Moscow Aviation Institute (National Research University) \\ 4 Volokolamskoe Shosse, Moscow, 125993, Russian \\ Federation \\ E-mail: tsvykirina@mail.ru
}

\begin{abstract}
The article is devoted to the analysis of the informatization process of all forms of educational activity and evaluation of its possible consequences. The authors consider the positive and negative aspects of the widespread introduction of computer technologies in the educational process. It is noted that computer technologies can significantly improve the productivity of self-training of students, ensure the development of their personality, stimulate research activities and generally increase the level of independence in the learning process. However, in the ethical plan, the possible dehumanization of the educational process, the departure from it of the spiritual personal component, may become the most dangerous consequence of the mass transition of the educational process to computer training schemes.
\end{abstract}

Keywords-education; information technologies; computer technologies; information society; teacher; creativity; personality

\section{INTRODUCTION}

Among the most important characteristics of the development of mankind in the twentieth century, it is first of all necessary to single out such a phenomenon as the emergence of computers and the beginning of the formation of information societies. The use of computer technology to create, store, transmit and use information required the creation of a whole direction in science, which received the name of computer science. The 1980s became a period of mass computerization in developed countries, where the number of computers of different types, annually on sale, primarily personal computers, amounted to tens of millions. The market of electronic commerce by 2016 has grown to 2 trillion. (For comparison, in 2002 it was $\$ 300$ billion, in 1956 - $\$ 2.6$ billion) [1].

Computerization significantly affects the learning processes, the formulation and solution of scientific problems, research in the field of thinking and cognition processes. Information and communication technologies (ICT) have become a powerful transformer of economic,

*This paper was financially supported by the Ministry of Education and Science of the Russian Federation on the program to improve the competitiveness of Peoples' Friendship University (RUDN University) among the world's leading research and education centers in the 20162020. (The Agreement number 02.A03.21.0008). social and other activities. The process of computerization and informatization is uneven in different countries and regions, but as a whole it has already progressed so much that it became possible to sum up some results and make a forecast for the future. The computerization of all spheres of human activity today is both the most important task of society, and as an imperative of social development. Without the solution of this task, humanistic transformations, the economic development of society, which can ensure a dignified life for all its citizens are impossible.

The rapid development and dissemination of new information and communication technologies as a result of scientific and technological progress is now acquiring an unprecedented scale of information revolution, which has an increasing impact on politics, economics, science and other spheres of society, both within national borders and in the world, as a whole. Information and knowledge are becoming one of the strategic resources of the state, the scale of its use has become comparable with the use of traditional resources, and access to them is one of the main factors of socioeconomic development. The constantly growing role of this factor as a means of accelerating the pace of global integration in the economy and the instrument of influencing mass consciousness, culture and international relations allow us to speak about the emergence of objective prerequisites for a movement towards the so-called "global information society".

\section{THE ROLE OF INFORMATION TECHNOLOGIES IN THE} FORMATION AND DEVELOPMENT OF INFORMATION SOCIETY

The rapid development of computer technology and ICT stimulated the development of a society built on the use of information and knowledge, which was called the information society. In accordance with the concept of $\mathrm{Z}$. Brzezinski, D. Bell, O. Toffler, supported by other foreign scientists, the information society is a kind of postindustrial society. Considering social development as a change of stages, advocates of this concept of the information society associate its formation with the dominance of the "fourth", information sector of the economy, following the three wellknown sectors - agriculture, industry, service economy. At 
the same time, they argue that capital and labor, as the basis of an industrial society, give way to information and knowledge in the information society.

There are various criteria for determining the fact of the transition of society to the information stage. So, as a criterion for the transition of society to the postindustrial stage and further to the information stage of development, the percentage of the population engaged in the service sector can be: if in a society more than $50 \%$ of the population is engaged in the service sector, the post-industrial stage has entered; if in a society more than $50 \%$ of the population is employed in the field of information services, then the society has become informational. According to this criterion, for example, the USA entered the post-industrial period of its development in 1956, and the information society became in 1974. In the 80's of XX century Japanese Institute of the Information Society was established in Japan. Its director, J. Masuda, writes in his works that new information technologies will lead to cardinal changes in people's value orientations: from narrow, direct, selfish they will turn into such ethical guidelines that will take into account the interests of all mankind. Thanks to informatization of all kinds of activities and the emergence of a new intellectual person, Masuda asserts, modern society will turn into a polycentric global society based on collectivism and competition [2].

Many Russian authors dealing with the research of the problem of the information society believe that in such concepts the elements of a social utopia clearly appear. However, it would be a mistake, in their opinion, on this basis to reject the very approach to the study and evaluation of new trends in the development of modern society. A.I. Rakitov, for example, distinguishes the following characteristics of the information society: a) accessibility of information; b) real availability of information, first of all technical; c) production of information in the amounts necessary and sufficient to ensure the life and development of society in all its parts and directions; d) accelerated automation and robotics in all spheres of production and management; e) the primary development of the field of information activities and services, so that at least $50 \%$ of the employed population work in these areas (with the preservation of the importance of the sphere of material production) [3].

One of the important social consequences of the informatization of society is the change in the nature of human labor. The main type of labor in modern society is labor associated with the transformation of information flows. To the power of the brain of an individual person joins the power of universal intellect, concentrated in programs introduced into computers. Thus, the habitual task of using our own intellectual abilities for the majority of workers using information technology turns into the task of selecting and using certain programs that allow, at the optimal time, to process and provide the information necessary for making decisions and organizing practical activities. Practical activity itself is substantially transformed, especially in the sphere of material production, since automation and robotics change the position of the worker's man in the production system, removing from him the function of an appendage to a particular machine. In addition, information flows, in the presence of computer technology, can be processed in any conditions. A consequence of this is a significant change in the distribution of workers in the places of their work [4].

The consequence of the globalization of the processes of informatization in modern society has been a change not only in the content of our knowledge of the world, but also in the ways in which they are acquired, reproduced and transmitted, which ultimately affects the internal structures of the individual. Many modern researchers of personality problems note that the person formed in the old school and the old type of university, in terms of its internal psychological characteristics, differs from that who already plays computer games in the kindergarten, goes to computer classes at school, works at a computerized workplace and communicates with friends via satellite. Under the influence of new ICT, the style of thinking, ways of communication, assessment of others and self-esteem are changing. The problem of computer dependence of a person becomes very actual [5].

The emergence and spread of the Internet poses the question of what in the coming years will become the main source of information for a person - the media or a computer network. The Internet is a world information computer network, which is rightly called the World Wide Web. It unites a multitude of computer networks operating under uniform rules and has its users in almost all countries of the world. The Russian branch of the research group GfK (Gesellschaft fur Konsumforschung) Group, January 26, 2017 published a report "Trends in the development of the Internet audience in Russia." According to the data in this report, the audience of Internet users in Russia at the age of 16 and older remained at the level of $2015-70.4 \%$, which is about 84 million people. The penetration of the Internet among young Russians (16-29 years old) has reached the limit values in previous years and, according to GfK, is $97 \%$. [6]. Thus, it can be stated that the Internet is the most important infrastructure of the developing information society. Speaking about the peculiarities of the Internet, it should be noted: - a broad audience of users and the possibility of its unlimited expansion; - cross-border dissemination of information; - high speed and efficiency of providing information; - virtually unlimited choice of sources and types of information; - practical absence of preliminary control of the content of information; - the opportunity to discuss emerging issues in real time.

\section{EDUCATIONAL PROCESSES IN THE INFORMATION SOCIETY}

Education is a well-established process of processing and obtaining knowledge, through the centralized systematic training of a group of people for a certain period of time. Thanks to education, people for many centuries adopt the vast experience of skills and knowledge accumulated by civilization for all of its existence. Cognitive purposeful activity of people in obtaining and improving skills and knowledge is the main driving force of scientific and technological progress. In this context, it is very important to 
define the content boundaries of the very concept of "education", the ethical aspects of which are determined in each particular case because of its multivalued nature. Education is: a) a social institution whose main function is to prepare and incorporate the individual into various spheres of society's life; b) the set of systematized knowledge, skills (especially professional ones) acquired by the individual (independently or in the process of training in special educational institutions); c) the process of mastering knowledge, i.e. education; d) the level of education of an individual with versatile knowledge and a high degree of culture; e) the education of society, the people, as a level of civilization of the country. For ethics in all the cases listed above, it is decisive to consider education not only in its educational plan, but mainly as "education", "creation" of the person [7].

The Law on Education of the Russian Federation states that education is a single, purposeful process of education and training, which is a socially significant benefit and is carried out in the interests of the individual, family, society and the state, as well as the totality of acquired knowledge, skills, values, experience and competence of a certain amount and complexity for the intellectual, spiritual, moral, creative, physical and (or) professional development of a person, satisfaction of his educational needs and interests [8].

The process of education includes:

1) education - activities aimed at the development of the individual, creating conditions for self-determination and socialization of the learner on the basis of socio-cultural, spiritual and moral values and accepted in society rules and norms of behavior in the interests of man, family, society and the state;

2) learning is a purposeful process of organizing the activities of learners in mastering knowledge, skills, competencies, acquiring experience, developing abilities, acquiring the experience of applying knowledge in everyday life, and forming motivation for students to receive lifelong learning;

The level of education is a complete cycle of education, characterized by a certain single set of requirements. The system of education is a set of educational institutions, built and functioning on the basis of general principles. In addition to institutions, this system includes educational programs and standards implemented by them, as well as education management bodies. The features and level of development of the system are determined, first of all, by the development of production; in addition, the level of development of culture in its broad sense and of science in particular; peculiarities of forms of social consciousness: ideology, morality, religion; finally, historical experience and national traditions. In addition, education depends on public policy (financing, social order, etc.).

The factors that determine the education system are dynamic, and therefore the education systems are periodically reformed to satisfy the needs of both society and the individual. The education system is a model that unites various institutional structures, such as schools, universities, pre-school educational institutions and colleges, for one common goal - to educate people who are learning in them. In each country the education system has a number of its features, but, on the whole, it guarantees the possibility of high-quality, timely and sometimes free education. It is the educational institutions that are the most important agents of the professionalization of the individual in modern society [9].

With the general computerization of socio-cultural reality, the processes of informatization of all forms of educational activity, the wide introduction of information computer technologies into the educational process are connected. The term "technology" is most often defined as a set of methods and techniques for processing or processing raw materials, materials, products and converting them into consumer goods. Modern understanding of this term includes both the method of determining (describing) and the sequence of actions in the process of cognition of the studied factors and phenomena. In this case, information and communication technologies can be considered such technologies, which are aimed at processing and transformation of information.

\section{COMPUTER TECHNOLOGIES IN MODERN EDUCATION}

Computer information technology is a complex of areas of activity that relate to the technologies of creation, storage and processing of information data using computer technology. The technical means of computer information technology include computers, software, the Internet and a network. They allow you to create, store, process, transfer and distribute a wide range of information resources.

Computer technologies are actively used to transfer information and provide interaction between the teacher and the trainee in modern systems of open and distance education. A modern teacher should not only have computer literacy, but also be able to apply a variety of computer technologies in their professional activities.

The main means of implementing computer technologies in the educational process of any level is a personal computer whose capabilities are determined by the software installed on it. The main categories of software are system and application (training) programs, as well as tools for software development. The system programs, in the first place, include operating systems that ensure the interaction of all other programs with the equipment and the interaction of the user of the personal computer with the programs. This category also includes service or utility programs. Applied programs include software that acts as a tool for working with texts, graphics, tabular data, etc. In modern education systems, universal office applications and tools are widely used: text editors, spreadsheets, presentation preparation programs, database management systems, organizers, graphic packages, etc. [10].

A fundamentally new quality has been acquired by education with the advent and spread of computer networks, which has radically changed the way information is received. Through the global computer network Internet, instant access to global information resources (electronic libraries, databases, file storage, etc.) is possible. In the most popular 
Internet resource, about two billion multimedia documents are available for reading and working.

In the network, other popular means are available to the user, including e-mail, mailing lists, newsgroups, and chat. Special programs for real-time communication have been developed, which allow you to transmit text, entered from the keyboard, and also sound, image and any files after the connection is established. These programs allow you to organize the work of remote users with the program running on the local computer.

To provide effective information retrieval in telecommunication networks, there are automated search tools, the purpose of which is to collect data on information resources of a global computer network and provide users with a quick search service. With the help of search engines, you can search for World Wide Web documents, multimedia files and software, targeted information about organizations and people.

The use of computer technology in the educational process is designed to solve important didactic tasks. First of all, it is the improvement of the organization of the educational process, the acceleration and intensification of the learning process, ensuring its flexibility and individual approach. In addition, computer technology can significantly improve the productivity of self-training students, ensure the development of their personality, stimulate research activities and generally increase the level of independence in the learning process.

With the help of network tools, it becomes possible to have broad access to educational, methodological and scientific information, the organization of operational consulting assistance, the modeling of research activities, virtual training sessions (seminars, lectures) in real time. A powerful technology that allows you to store and transmit the bulk of the study material is educational electronic publications, both distributed in computer networks, and recorded on electronic media. Individual work with them gives a deep understanding of the material. These technologies allow, with appropriate refinement, to adapt existing courses to individual use, provide opportunities for self-study and self-examination of acquired knowledge. Unlike traditional books, educational electronic publications allow you to submit material in a dynamic graphic form.

The emergence of computer technology has made it possible to create a qualitatively new educational environment as a basis for the development and modernization of the education system.

Computer technologies are key at all levels of the educational system. At each stage of cognitive activity, scientific research and in all branches of knowledge, computer technologies perform functions, both tools and objects of cognition. Thus, innovations in computer technologies provide a revolutionary development of the educational process. Computer technologies belong to a class of innovative technologies that provide a rapid accumulation of intellectual potential, which guarantees the sustainable development of society.
Computer technologies in the educational process opened new, previously unseen opportunities for the development of distance education, which previously existed in the form of distance education and faced many problems associated with the lack of necessary contact of the teacher with the student, poor control over the course of the learning process, etc.

Distance learning today is the acquisition of education through the Internet and modern computer technology. With distance learning, there is an exchange of educational information with the help of modern electronic and computer tools at a distance, thus, distance learning significantly expands opportunities for obtaining high-quality professional education. Computer technologies provide the operative delivery to the trainees of the main volume of the studied material, including electronic educational resources; provide interactive interaction of students and teachers, for example, during on-line discussions, round tables and seminars; guarantee a quick assessment of the knowledge and skills obtained during the training. Since the necessary part of the distance learning system is self-learning, with the help of modern computer technologies the student can study the material, using not only printed publications, but also videotapes, electronic textbooks and reference books, has access to electronic libraries and databases containing a huge amount of diverse information.

As the development and activation of the application of distance and e-learning, computer technologies increasingly assume the role of a significant social factor, which inevitably leads to the emergence of a number of situations requiring ethical regulation. Ethics of distance and e-learning, in addition to the generally accepted rules and norms of pedagogical ethics and ethics of higher education, also includes separate elements of computer ethics - a special field of research dealing with ethical issues arising from the development and application of computer technology. Of course, the computer itself does not change and can not change ethical norms and regulations, it only, as A.S. Kapto aptly notes, "increases, and substantially, the technical and operational opportunities for immoral people to harm for their personal or corporate purposes" [11].

An important role in the ethics of distance learning is also played by the communicative competence of business entities. It includes the traditional forms of business correspondence that were established 150 years ago in England (etiquette of business correspondence, letters of appreciation, press releases, other official documents), as well as the norms of the so-called electronic etiquette (netiquette), i.e. ethical rules of working on the Internet, with e-mail, mobile phones, etc. The norms of electronic etiquette are an extensive sphere of rules, the lighting of which requires a separate topic. As an example, the following simple rules for electronic correspondence are given here: 1 . The e-mail must be correct and correctly filled. 2. You should always check the correctness of writing the address and the name of both the recipient and the sender. 3. For faster identification of your letter, the recipient should always briefly and clearly indicate the subject of the letter. 4 . Answering the letter, pay attention to whether you should change the subject of the letter. 5. Before sending a letter it is 
advisable to save it in a separate file. 6. An e-mail, like a regular letter, must comply with accepted business correspondence rules, abbreviations and jargon are inadmissible. 7. You must always respond to emails, or confirm their receipt. 8. With electronic correspondence, you should be especially careful with confidential information. 9 . You can not publicize or publish information from personal letters without the consent of their senders [12].

\section{ETHICAL PROBLEMS OF COMPUTERIZATION OF THE EDUCATIONAL PROCESS}

Modern social reality, based on information and knowledge, requires a person to create the skills to receive new knowledge, creatively transform them and solve complex problems on their basis. A serious tool to meet these requirements is the computer information technology used in teaching. Competently organized educational process with the use of modern innovative technologies allows to form necessary skills and abilities, contributing to the development of such important for the future specialist qualities as intuition, professional flair, flexibility and creativity of thinking, analytical abilities. Therefore, the full implementation of computer information technologies, of course, should become one of the priority tasks of the information educational policy of our society and the state.

The computer revolution significantly changes the traditional methods of education, gradually displacing the teacher from the teaching process. Using the computer as the latter gives fundamentally new moral and educationalmethodological parameters, making some routine functions of the teacher's profession unnecessary (especially verbal methods of teaching). This brings a completely different vector to the treatment of the category "pedagogical impact" with a clearly expressed tendency to reduce external (from the teacher's side) impacts and build up the inner potential of the individual in her cognitive activities (self-education, independent search for the most acceptable computer solutions, self-control, etc.) [13].

At the same time, it would be a serious misconception to represent the prospects for a complete transfer of the educational process to electronic-digital methods of teaching only in romantic and iridescent colors. The global nature of the processes of universal computerization has led to an exacerbation of many social and moral problems that fully affect the institution of education and generated new negative collisions. Computerization affects the economic and psychological reorientation of man in the world around him, forms a completely new ethical situation in society, changes the behavior of people, and not only for the better. The transformation of computer technologies into an integrated part of the educational process put forward a number of new moral problems. The global introduction of computer technologies into the educational process, and especially the desire to replace them with traditional educational technologies, can create many problems and, ultimately, lead to a serious impoverishment of the educational process, which can turn from the most complex creative process of "building" a person into a primitive, although high speed and volume, information transfer.
Among the negative consequences of the use of computer technologies in all forms of training, it is possible to single out the possible negative impact of computer technology (with its long application) on the physiological state and health of both educators and students. It should be noted that many hours of work with computers, printers, e-mail, etc. is very dangerous for human health. Those who often deal with computer processing of information have a disease, which experts call the "information fatigue syndrome" - a state where a person loses the ability to adequately perceive information and make right decisions on its basis. Such a state can significantly impede the normal course of the educational process.

However, the most dangerous consequence of the complete transfer of the educational process to computer tracks seems to us to be the possible curtailment of the live dialogical communication of the participants in the educational process - the communication that is the most important and practically the only source of speech development for the students and, consequently, their independent creative thinking. Without a developed practice of direct dialogue - a teacher with a student, students among themselves, etc. - it is impossible to form the ability to correctly and accurately formulate your thoughts in a professional language, and hence the full professional and personal formation of students. "Dialogue with a computer" instead of living human communication during the educational process acts as a surrogate for communication and is unable to fully replace it. Minimizing the live, direct contact of the teacher and student, replacing their communication in the course of traditional forms of education, such as lectures, seminars, personal consultations, various "advanced" educational technologies (teaching computer programs, audio and video courses, etc.) we run the risk of missing out the very possibility of forming creative thinking, which, by its very origin, is based on dialogue.

Thus, like any technical achievement, computer technologies have negative consequences, including the sphere of education. So, in the cognitive-mental aspect, this is the formation of non-linear, associative, mosaic thinking, an overabundance of information, the weakening of creative principles in man. In the humanitarian aspect, information technologies mechanize and standardize educational activities, impersonate the learning process, and weaken the humanitarian aspects of education as a whole.

In ethical terms, the most dangerous consequence of the mass transfer of the educational process to computer training schemes is the possible dehumanization of the educational process, the departure from it of the spiritual personal component, which in the course of using traditional teaching technologies was provided by the personality of the teacher, his moral and spiritual impact on the students.

\section{CONCLUSION}

Summarizing the above, we note the following. In the modern world, in the conditions of a developed information society, information, communication, and computer 
technologies reveal unprecedented opportunities for educational growth and self-improvement, and it largely depends on the person himself whether we can properly dispose of these opportunities. Recognizing the obvious need and usefulness of the active introduction of computer technologies in the educational process, it is necessary to harmoniously combine new technologies with traditional educational practices during this implementation. After all, if at present the Russian education system retains its positions, it is due to a reasonable combination of valuable and courageous innovations with a peculiar traditional stability of functioning, while preserving the humanistic, ethical, value component of the educational process. It is in this combination the key to successful modernization of the educational system.

The profession of a teacher, like no other, requires constant creativity. Forming his moral and ethical preferences, his scientific worldview, his professional consciousness, the teacher is also the creator of the same spiritual values for the youth. And if moral degradation, as a rule, is a consequence of the philosophical vacuum, the ideological and spiritual facelessness is born in the conditions of unprocessed or distorted moral orientations of the person, contributing to its increasing distance from the higher spiritual values. Educational institutions can only fulfill their basic social task when, during the learning process, knowledge is not simply transferred, but also the consciousness of students with higher spiritual values is enriched, and the creative personality is formed. Therefore, nothing, even the most sophisticated electronic means can replace the personality of the teacher, the teacher, transforming students into their own professional and moral values: concern for constantly growing skills, high consciousness, ideological and spiritual maturity and moral purity.

\section{REFERENCES}

[1] Trends in the global e-commerce market 2015-2016. - URL: https://profi-site.info/e-commerce.html

[2] Masuda Y. The Information Society as Postindustrial Society. Wash .: World Future Soc., - 1983.

[3] A.I. Rakitov. The philosophy of the computer revolution. - M., 1991. - 287 p.

[4] History and Philosophy of Science (Philosophy of Science): Textbook / E.Yu. Belskaya [and others]; Ed. Prof. Yu.V. Kryanev, prof. L.E. Motorina. - 2 nd ed., reedited and additional.- Moscow: Alfa-M: INFRA-M, 2012. - 416 p.

[5] Tsvyk I.V. Computer Ethics and Problems of Intellectual Security // Bulletin of the Russian University of Peoples' Friendship. Series Philosophy. - 2013. - №3. - P. 125-134.

[6] The number of Internet users in Russia. - URL: http://www.bizhit.ru/index/users_count/0-151

[7] Tsvyk V.A. Ethics of Higher School (on the example of the Russian University of Peoples' Friendship) // Bulletin of the Russian University of Peoples’ Friendship. Series Philosophy. - 2016. - № 3. P. 9-18.

[8] The Law of the Russian Federation "On Education". - M., 2012.

[9] Tsvyk V.A., Tsvyk I.V. The Role of Educational Institution in the Professional Development of the Person in the XXI Century // Proceedings of the 2016 International Conference on Art, Design and
Contemporary Education. ICADCE 2016. Vol. 64. - Atlantis Press, Paris - France. - P. 1274-1279.

[10] Information and communication technologies in education / Ed. B. Dendeva - Moscow: UNESCO IITE, 2013. - 320 p.

[11] Kapto A.S. Professional Ethics. - M., 2006. - 800 p.

[12] Ethics of higher education / V.A. Tsvyk, I.V. Tzvyk and others. Moscow: Publishing House of the PFUR, 2016. - 210 p.

[13] Lapshin I.E. Higher education as a factor of socialization of modern youth: the ethical aspect // Bulletin of the Russian University of Friendship of Peoples. Series Philosophy. - 2016. - № 3. - P. 88-95. 